\title{
La historia oral en la arquitectura urbana (1940-1990)
}

Graciela de Garay

INSTITU'TO MOR A

$\mathrm{E}$ 1 proyecto de Historia Oral de la Ciudad de México. Testimonios de sus Arquitectos (1940-1990) tiene por objeto registrar, mediante entrevistas grabadas, los testimonios de los principales testigos y actores de la historia de la construcción de la ciudad, ocurrida en los últimos cincuenta años. ${ }^{1}$

Una vez definidos los arquitectos

1 El Proyecto de Historia Oral de la Ciudad de México. Testimonios Orales de sus Arquitectos (1940-1990) comenzó en enero de 1990 y concluyó en su primera fase en junio de 1993. La investigación está patrocinada por el Instituto de Investigaciones Dr. José María Luis Mora. Para la realización de la segunda etapa (agosto 1993. julio 1994) el proyecto ha recibido el apoyo fi. nanciero del Consejo Nacional de Ciencia y Tecnología. como los informantes más idóneos para este trabajo, y elaborada la lista de testigos -que distribuí en dos generaciones-, comencé las sesiones de grabación.

Conforme avancé en el rescate de testimonios vi que los informantes hablaban poco de la ciudad, es más, decían verdades compartidas, y sus relatos se limitaban exclusivamente al desarrollo de sus principales obras y, en el mejor de los casos, a la relación de sus trabajos con el contexto urbano. Obviamente, en un principio, esto resultó alarmante. La investigación perdía sentido, ya que no se buscaba hacer una historia de la arquitectura sino una historia urbana.

La verdad es que esta objeción se 
superó al reconocer la definición del arquitecto como responsable de la be. lleza de las formas construidas $y$, en última instancia, de la ciudad como expresión de un conjunto estético, pues es claro que la arquitectura es un arte. ${ }^{2}$ Corresponde entonces aclarar que el diseño de la forma urbana compete fundamentalmente a los políticos y a los planificadores, detentadores del poder y de la economía, sobre todo cuando se trata de la ciudad social y, en términos más modernos, de la ciudad económica. Pero de este punto haré mención en otro apartado.

Un segundo problema, que resultó desconcertante y replanteó la validez de la investigación, se derivó de la composición misma de la muestra de informantes elegida. Se trata de un conjunto de individuos que integran una elite homogénea, ligada al poder por encargo y tipo de demanda, y, en consecuencia, no representativa de una "arquitectura nacional". La objeción apuntaba entonces a la parcialidad de la información y a las dudas sobre su alcance.

Ante estas consideraciones me sentí obligada a explorar otros campos de la producción intelectual y averiguar si éstos en realidad constituían auténticas manifestaciones nacionales. Para tal propósito examiné aquello que creo conocer y tener más cerca: la creación historiográfica.

Efectivamente, era necesario preguntarse por el carácter nacional de la historia escrita. ¿Los historiadores re-

2 Véanse los currícula de las universidades del mundo y cómo éstas distinguen y separan al arquitecto del planificador y del político. flejan rigurosamente el punto de vista nacional o los intereses del grupo o clase al que pertenecen? Naturalmente, la respuesta mostró la naturaleza elitista del inventario historiográfico, defecto insuficiente para abandonar su estudio y despreciarlo como parte del patrimonio cultural.

Pues bien, después de estas reflexiones, proseguí con las entrevistas, de las que desprendí unas primeras conclusiones que, en esta ocasión, comparto con ustedes en espera de escuchar opiniones y críticas que puedan enriquecer el trabajo.

\section{INTRODUCCIÓN}

E. H. Carr explicó que el historiador, antes de empezar a escribir historia, es producto de la historia. ${ }^{3}$ Por mi parte, establezco una relación semejante para el arquitecto. Y para aclarar este punto retomo dos ideas fundamentales del autor inglés: primera, no se puede comprender o apreciar plenamente el trabajo de un historiador sin conocer primero el punto de vista desde donde lo escribe; segunda, que ese punto de vista está enraizado en un espacio histórico y social. ${ }^{4}$

Para reforzar este planteamiento como premisa fundamental de mi trabajo y punto de controversia, me referiré a E. Bradford Burns, quien en su artículo dice:

Cuando los historiadores representan un grupo relativamente homogéneo, sus historias tienden a perpetuar una

3 Carr, What, 1986, p. 34.

4 lbid. 
similitud al atribuir al pasado una uniformidad más acorde con la perspectiva de elite que con la totalidad de la experiencia. 5

Tales restricciones caracterizan, a mi juicio, a la arquitectura de la ciudad de México de los últimos cincuenta años.

Sin embargo, comparto con Burns su temor al asegurar que esa uniformidad refleja un criterio de elite más que un punto de vista nacional. Ciertamen. te, sugerir que la arquitectura de la ciudad de México, tema de esta inves. tigación, representa más a una elite

5 Burns, "Ideology", 1978, p. 409. De acuerdo con Vilfredo Pareto, los grupos de personas mejor calificadas de cualquier actividad conforman una clase que se debe definir como una elite. Para Pareto el concepto de "elite" sirve para subrayar las desiguales capacidades o talentos de los individuos en cualquier esfera de la vida social y como punto de partida para la defi. nición de la elite gobernante. Por tanto, deben distinguirse dos clases de elites: la gobernante integrada por individuos, que directa o indirec. tamente juegan un papel importante en el gobierno, y una no gobernante que incluye el resto. De esta manera contamos con tres estratos: uno más bajo que no pertenece a la elite y cuya influencia en el gobierno no interesa discutir en este trabajo, y otro más alto, representado por la elite, que se divide en dos: la elite gobernante y la elite no gobernante. Sin embargo, para Pareto la diferencia esencial está entre los que tienen poder, la elite gobernante, y los que no tienen, las masas. Las elites para Mosca representan, de alguna manera, los intereses y propósito de importantes e influyentes grupos de la sociedad. Las elites cambian periódicamente la composición de sus miembros integrando nuevos que reclutan de otros grupos de la sociedad, y oca. sionalmente se da el reemplazo completo de la vieja elite por una contraelite, a como ocurre en las revoluciones. Citado por Bottomore en Elites (1964-1973), pp. 7-12. Véase sobre la teoría de las elites: Boudon y Bourricaud, "Elites", 1980. que a un punto de vista nacional, es una acusación muy seria. Para sostener tal afirmación es necesario estudiar los estilos de vida de un número suficiente de estos arquitectos para ver si verdaderamente surgen pautas comunes y, al analizar sus ideas, determinar si la similitud las caracteriza.

\section{DEFINICIÓN DEL OBJETO DE ESTUDIO}

Antes de entrar en materia quisiera definir mi objeto de estudio - los arquitectos de la ciudad de México- para distinguirlos de profesionales afines que comparten el mismo campo pero que ejercen su actividad profesional desde posiciones, métodos y perspec. tivas diferentes.

Como señala Lisa R. Peattie, no existe ninguna representación de la realidad que sea neutral. Existen muchas maneras de ver el mundo. Cualquier interpretación de la realidad se desprende de un conjunto de intereses en el mundo real. Cualquier visión de la realidad sugiere un modelo de acción sobre ésta -aun cuando ese modelo de acción implique dejar a la realidad actuar por sí sola. Las formas de ver son instrumentos o partes de una estrategia para la acción. ${ }^{6}$

Una ciudad, aclara la antropóloga citada, se puede pensar como un marco construido -edificios, espacios abiertos, pasajes, barreras. Se le puede concebir como un sistema de reglas o reglamentaciones- impuestos, reglamentos de construcción, leyes para la propiedad y tenencia de la tierra. Se le

$$
6 \text { Peattie, "Planning", 1991, p. } 35 .
$$


puede imaginar como un espacio del poder donde se establecen los acuerdos políticos que organizan el poder. También puede aparecer como un sistema económico -inversión de capital, oferta de trabajo, habitación y mercados de suelo. ${ }^{7}$

En realidad, cualquier ciudad es la suma de todos estos elementos, ya que cualquier representación ref leja un aspecto de la realidad y cualquiera de ellas lleva finalmente a otras. Sin embargo, la diferencia está en el punto de partida.

Por ejemplo, el arquitecto contempla un mundo de formas construidas. Las formas son fundamentales. Prácticamente todos los arquitectos desean

7 Ibid. construir en grande, edificios bellos y nobles; pero poco les preocupa saber de dónde vienen los recursos y quién debe ceder en el proceso. La gente se presenta en sus concepciones como usuarios, beneficiarios o víctimas de sus logrados o fallidos modelos.

El urbanizador, consciente de las reglas que rigen la construcción, se concentra en la envoltura de la zonificación y en el sistema político que debe manipular. Su percepción de la ciudad no se refiere a las construcciones edificadas sino al valor del terreno y sistemas de reglamentación; la tarea del urbanista es producir paquetes de beneficios, ganancias y utilidades.

El político ve a la ciudad como las distintas manifestaciones del poder;

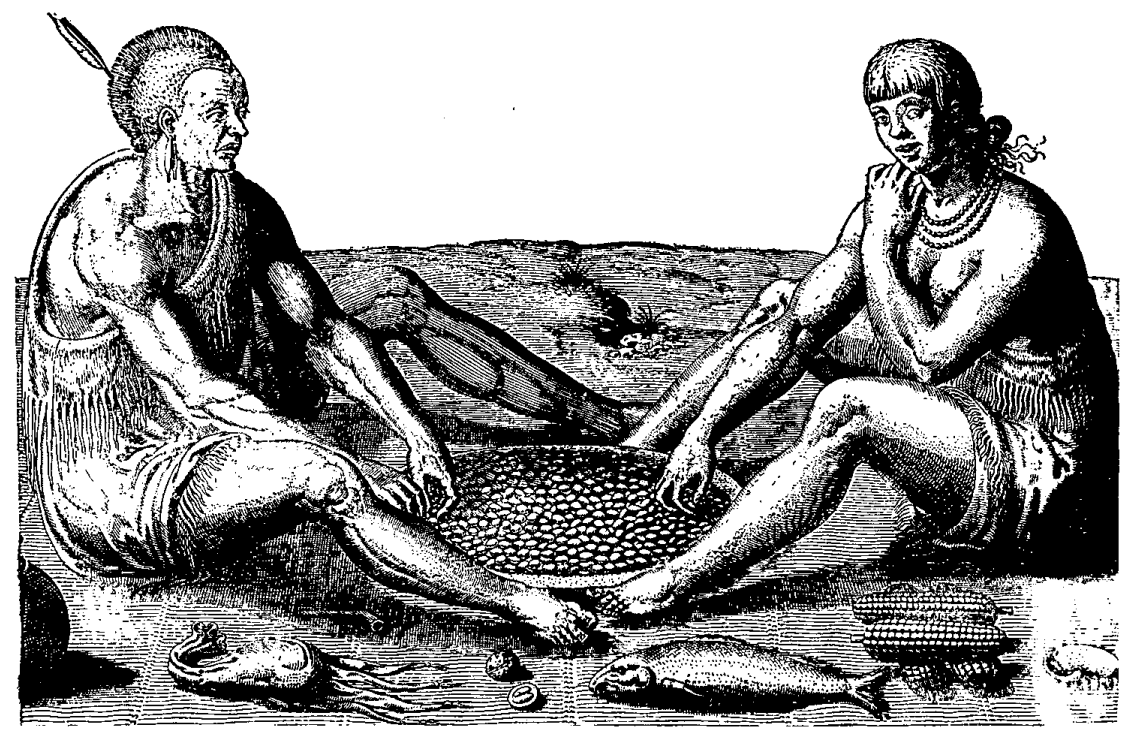


algunas institucionalizadas, otras como formas más débiles de sociedades o comunidades de grupos dispersas en las calles pero susceptibles de ser organizadas para que, comodicen algunos, echen a andar la maquinaria.

Cada una de estas visiones del mundo es diferente, pero todas y cada una de ellas ha contribuido significativamente a configurar la realidad en que vivimos. Sin duda, la que atañe a la esfera del poder es la decisiva. En la actualidad prevalece el modelo que ve a la ciudad como un sistema económico, un espacio para que se desarrollen proyectos de sociedades públicas y privadas, es decir: el gobierno y entidades lucrativas. De esta manera, hasta el gobierno se vuelve partícipe de un negocio rentable: la ciudad.

De cualquier manera, la ciudad como un espacio ético y político incorpora $-o$ debe incorporar- los valores que comparten tódos sus habitantes. Sin embargo, un enorme número de marginales urbanos prueba que lo contrario es cierto.

El entendimiento de los asuntos urbanos y arquitectónicos está restringido a un pequeño segmento del público especializado y profesionalmente entrenado. En consecuencia, mucho del ambiente físico se desconoce y resulta incomprensible a la gran mayoría de sus habitantes, aun cuando sin quererlo son los verdaderos diseñadores de la ciudad. ${ }^{8}$

Si pudiéramos, como señala Paolo

\footnotetext{
8 Véanse los proyectos de ciudad que se han realizado en México desde la época de la colonia a la actualidad. Cfr. trabajos de Rafael López Rangel, Jorge Legorreta, Javier Delgado.
}

Polledri, reconstruir esta dimensión perdida de la sociedad y sus espacios, arquitectos, planificadores y políticos podrían ser los líderes al imaginar un entorno urbano lo suficientemente variado que reflejara los cambiantes valores de sus habitantes, pero lo suficientemente coherente para desarrollar una comunidad. 9

Este estudio no intenta presentar una visión del futuro del arquitecto de la ciudad de México, sino la necesidad urgente de definirle un papel más amplio y socialmente más responsable. La fragmentación y falta de cohesión social que caracteriza a la ciudad de México así lo reclama.

\section{METOdología}

Este ensayo se apoya en la metodología de la prosopografía, mejor conocida como biografía colectiva, así como en la metodología y técnicas propias de la entrevista de historia oral. Con esta investigación intento distinguir tanto los comunes denominadores de los estilos de vida de los entrevistados, como las mentalidades e ideologías que adoptan como modelos para sus proyectos. Concluyo que la arquitectura que construyen refleja su particular y exclusiva posición social. En breve, supongo que los espacios que edifica el arquitecto profesional en la ciudad de México, entre los años 1940 a 1990, se conforman a partir de la construcción de una realidad socialmente limitada. ¿Y cómo podria ser de otra manera, si lo que caracteriza a la realidad de la

9 Polledri, "Dreamscape", 1991, p. 20. 
ciudad de México es la heterogeneidad y el contraste?

Los arquitectos que integran la muestra nacieron entre 1908 y 1933 , y son importantes porque jugaron un papel intelectual y artístico poco común en la historia de la construcción de la ciudad de México.

Al seleccionar lo que imaginé una muestra representativa de arquitectos, intenté la relación equilibrada entre dos grupos y generaciones de la elite profesional que abarcara desde los más conocidos o populares, por el volumen y diversidad de obras, hasta otros menos evidentes pero también con un número considerable de trabajos, tal vez menos diversificados o más concentrados en una realidad o sector, sin dejar de ser, por eso, importantes o afamados.

La lista, aunque pequeña, de apenas doce informantes hasta el momento, ${ }^{10}$ resultaría inaceptable si excluyera, por un lado, a las figuras protagónicas que además de influir en su propia generación lo hicieron en las siguientes; por el otro, a las personalidades menos evidentes por volumen de obra pero valiosa, cualitativamente, porsus contribuciones al diseño del perfil urbano. Las opciones lógicas, comprendidas dentro de la primera generación perteneciente a los nacidos entre 1908 y 1920 , aproximadamente, son Enrique Yáñez (1908), Héctor Mestre (1909), Mario Pani (1911), Manuel de

${ }^{10} \mathrm{~A}$ la lista de los doce entrevistados se piensa agregar, en la segunda fase, los nombres de los arquitectos Félix Candela, Pedro Ramírez Vázquez, Ricardo Legorreta, Juan José Díaz Infante y Francisco Artigas, que esperamos acepten. la Colina (1913), Augusto H. Álvarez (1914), Ernesto Gómez Gallardo (1918), Reinaldo Pérez Rayón (1918) y Ricardo de Robina (1919). De la segunda generación, nacidos entre 1920 y 1935 más o menos, y alumnos de los anteriores, inclúi los siguientes nombres: Agustín Hernández (1924), Abraham Zabludovsky (1924), Teodoro González de León (1926) y Luis Ortiz Macedo (1933).

Las divisiones temporales me permitieron adoptar un criterio generacional para organizar la muestra. La categoría "generación" la utilicé en sus dos acepciones: la sociobiológica y la estrictamente sociológica. En la sociobiológica la edad es fundamental. En este nivel interesa el significado sociológico subyacente en la dimensión de la edad.

En la acepción sociológica, la generación se entiende como

una comunidad vinculada por una experiencia social e histórica común o similar, experiencia que ha tenido lugar en etapas de la vida particularmente im. portantes para la formación de la personalidad. En este caso, la edad biológica es de importancia secundaria; una experiencia histórica social específica determina la afiliación generacional y la separación entre las distintas generaciones. ${ }^{11}$

De esta manera, la diferenciación de los sujetos a partir de las dimensiones sociobiológica y sociológica permite analizar la información recabada en dos niveles: en la microescala de la familia y

11 Tarkowska, "Diferenciación", 1991, p. 47; Chiara Saraceno, "La estructura", 1991, p. 46. 
en la macroescala de grupos más am. plios, como podría ser el gremio.

En un primer momento -en la generación sociobiológica- se distinguen los datos personales del sujeto y los relativos a su contex to familiar. En este ámbito es necesario establecer la diferenciación generacional de estilos de vida o la permanencia suprageneracional de valores y patrones dentro de la familia. En este sentido, la investigación no aportó información interesante. Se encontraron ejemplos de "conflicto generacional" o "diferenciaciones generacionales de estilo de vida", pero poco trascendentes porque no desintegraron a la familia, como la identificación con ideas liberales, socializantes o comunistas y, en algunos casos, el consecuente abandono de creencias religiosas. Tal es el caso de Enrique Yáñez, representante de la primera generación, y de Agustín Hernández, Abraham Zabludovsky y Teodoro González, miembros de la segunda.

En cuanto a los ejemplos de plena congruencia y continuidad de patro. nes de vida, estabilidad y costumbres, éstos se perciben en las relaciones del informante con los antecedentes sociales e históricos de su familia. Esta situación se capta claramente en los casos de Augusto H. Álvarez, Héctor Mestre, Mario Pani, Manuel de la Colina, Ernesto Gómez Gallardo, Reinaldo Pérez Rayón y Ricardo de Robina, todos integrantes de la primera generación. Lo mismo sucede con Luis Ortiz Macedo, de la segunda. Dentro de esta línea, es importante referir la situación de Augusto H. Álvarez, de la primera generación, asociado a Juan Sordo Madaleno, un arquitecto cuya familia contaba con excepcionales contactos sociales y económicos. $\mathrm{Ri}$. cardo de Robina, miembro de la primera generación, constituye otro ejemplo interesante, pues su primer cliente es su propio círculo social.

Existe también el caso de los arquitectos que cuentan con buen respaldo social pero además tienen compañeros y maestros que los invitan a trabajar con ellos. Dentro de esta categoría podría incluirse a Manuel de la Colina y su sociedad con Héctor Mest re. Algo semejante sucede con Ernesto Gómez Gallardo que, en la Escuela de Arquitectura, conoce a Santiago Greenham, con quien después hace obras en sociedad. Y de la segunda generación la sociedad más conocida sería la de Teodoro González de León y Abraham Zabludovsky.

Agustín Hernández, de la segundageneración, se asocia inicialmente con su hermano para luego separarse y comenzar una carrera independiente, pero claro, sin renunciar a los apoyos sociales derivados de los antecedentes políticos $y$ militares de su familia.

En cambio, cuando los arquitectos carecían de relaciones sociales privilegiadas, se establecía el vínculo maestro/ alumno como sustituto de la relación familiar. El maestro de la generación hacía las veces de contacto intermedio entre el cliente potencial, la mayoría de las veces el Estado, y el alumno que recomendaba. En la primera generación se distingue a Enrique Yáñez, cuyo contacto con el arquitecto José Villagrán García - maestro y padre de los arquitectos de ese grupo- es fundamental para su especialización en la arquitectura de hospitales. 


\section{SECUENCIA}

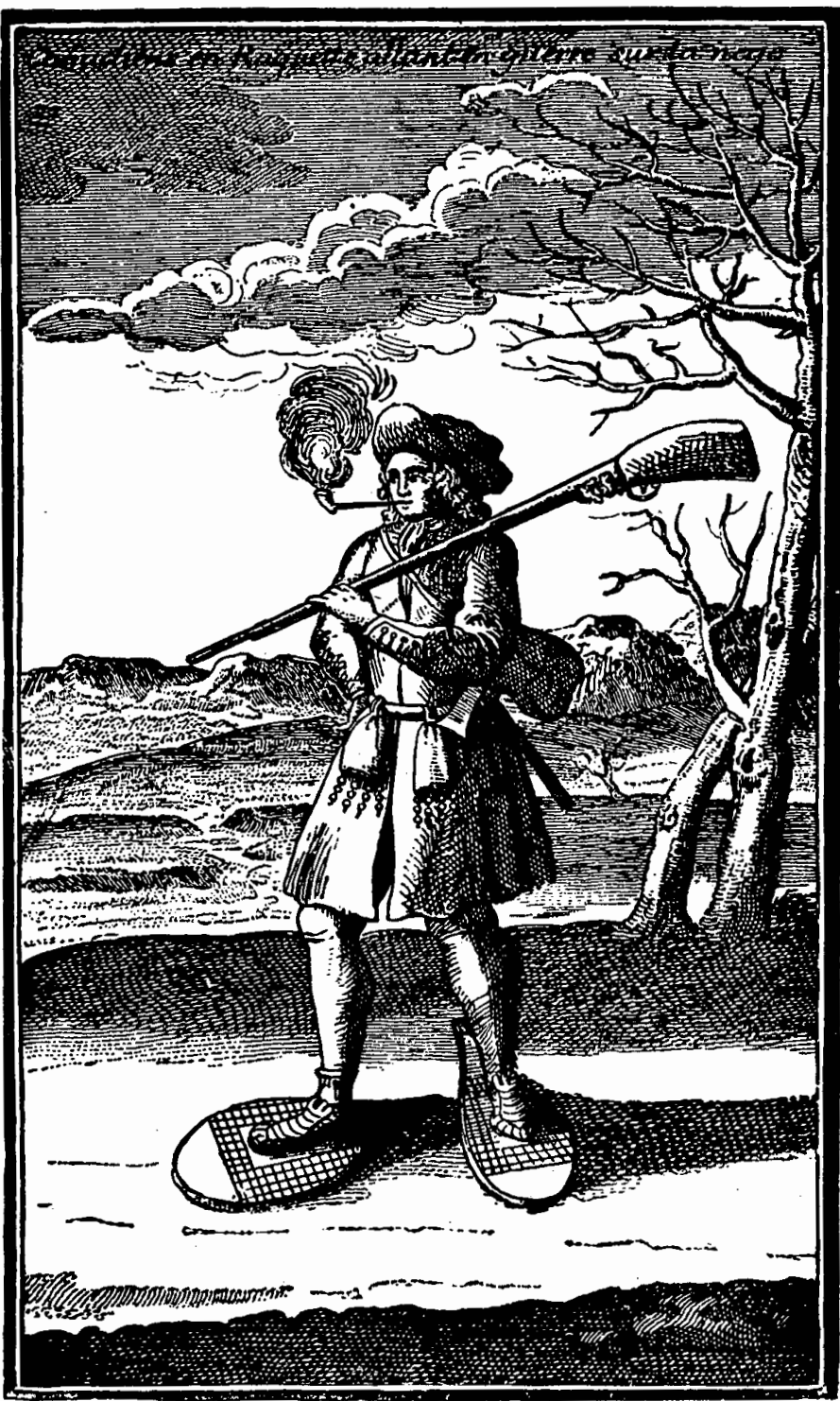


Pero también existe el caso del apoyo de instituciones del Estado que sirven de trampolín para el inicio de una carrera. Un buen ejemplo, dentro de la primera generación, sería el de Reinaldo Pérez Rayón, quien desde muy joven se integra a la oficina del Plano Regulador de la ciudad de México.

¿Y por qué no el cliente excepcional? Como ocurrió, por separado, a Teodoro González de León y a Abraham Zabludovsky, arquitectos de la segunda generación. Situación ésta muy reveladora de los cambios económicos ocurridos en el país a principios de la década de los cincuenta.

Ahora bien, en cuanto al nivel estrictamente sociológico, que ubica un acontecimiento histórico social como determinante de la afiliación generacional y la separación entre las distintas generaciones, cabe decir que la re. volución mexicana de 1910 marcóa la primera generación; mientras que los acontecimientos privados o típicamente personales prevalecieron en los testimonios de la segunda. Puede decirse que las narraciones de las personas de más edad son "historicéntricas", comparadas con las autobiográficas o "egocéntricas" de los jóvenes.

Estas diferencias sugieren diversas formas de ver el tiempo: la dimensión histórica está conectada a "la percep. ción colectiva del tiempo" que informa sobre hechos experimentados con otros, que trascienden la vida privada. La aproximación "egocéntrica" retrata una percepción altamente individualista del desarrollo de la propia existencia. ${ }^{12}$

12 Ibid., p. 50.
Sería pertinente averiguar cómo tales dimensiones o percepciones del tiempo se tradujeron en la formación de actitudes activas o pasivas en sus estilos de vida. Tal vez en la generación mayor se encuentra una inquietud permanente que resultó del ritmo acelerado de su propia historia colectiva, y en los más jóvenes predominó la estabilidad, surgida de la necesidad de la búsqueda de la propia estabilidad.

Los relatos de los informantes de la primera generación reflejaron, más amplia y significativamente en sus historias de vida, acontecimientos colectivos e históricos no privados. Mario Pani, Héctor Mestre y Augusto H. Álvarez hablaron de las buenas o malas relaciones de sus respectivas familias con la elite triunfante de la revolución, mostraron cómo este periodo de la historia de México afectó el curso de sus vidas.

En cambio, para los arquitectos de la segunda generación, digamos de la posguerra, los hechos de la experiencia personal son los más importantes, salvo la excepción de Abraham Zabludovsky, quien reflexiona sobre los cambios que se dieron en su vida cuan. do en los años veinte su familia de origen judio emigró de Polonia para establecerse en México.

Obstáculos de tipo técnico - una lista corta de informantes- me impidieron establecer una diferencia más precisa. No obstante, el propósito de localizar distinciones generales más esenciales me ayudaron a considerar fenómenos fundamentales.

Conviene mencionar que la segunda generación se siente muy ligada a la primera generación de maestros, y 
aunque en los más jóvenes sorprenden la inestabilidad de sus carreras, su movilidad social y profesional, la superación de diferentes obstáculos sociales y culturales, es posible advertir - a través de sus historias-una duda en cuanto a su capacidad de elegir, al inicio de sus carreras, su propio camino y configurar su propio destino al margen de los maestros. Véase el caso de Teodoro González de León cuando rompe con Mario Pani a propósito del proyecto de Ciudad Universitaria. La brusca separación del maestro afecta al alumno en una forma importante, tanto, que éste abandona el país para estudiar en Francia.

En general, al procesar los resulta. dos de la investigación distinguí como preocupación central de la segunda generación la necesidad de ser independiente o de incorporarse al Estado. Esto no significa que corte su vínculo con la primera generación; por el contrario, lo afirma desde etapa muy temprana al inscribirse, como dibujantes, en los despachos de los más connotados arquitectos de la época para reforzar los conocimientos escolares y aprender el oficio, pues como dicen los propios informantes del proyecto $y$, en particular, Teodoro González de León, la arquitectura se aprende haciéndola con el maestro. De esta manera predominó la continuidad de las generaciones al construirse un mecanismo para transmitir, conservar y defender los conocimientos del gremio. La elite, en vez de fragmentarse, se consolidó y prolongó su vida hasta la siguiente generación. Pero a este aspecto volveré más adelante.
LAS ELTTES: PERFILES BIOGRÁ FICOS, ESTILOS DE VIDA, IDEAS Y OBR AS

En este apartado considero los datos biográficos y académicos de los entrevistados, así como sus métodos de tra. bajo, ideologías y metas a alcanzar. Todo esto resume en buena medida las rupturas y continuidades de las generaciones que integran la elite arquitectónica de la ciudad de México.

\section{Perfiles biográficos y académicos}

Los cuestionarios base aplicados a los informantes permitieron construir un perfil general del grupo, a pesar de las sutiles diferencias individuales que aparecieron.

La muestra de doce entrevistados hasta el momento, incluye nueve arquitectos nacidos en la ciudad de Mé$\mathrm{xico}^{13}$ y tres en la provincia: Augusto H. Álvarez, originario de Mérida, Yucatán; Manuel de la Colina, nacido en Tulancingo, Hidalgo y Héctor Mestre de Puebla, Puebla. Los arquitectos que nacieron fuera de la ciudad de México se trasladaron a la capital a temprana edad para continuar sus estudios. Con motivo de la revolución de 1910 , la familia de Augusto $H$. Álvarez se exilió en Cuba algunos años, y posteriormente viajó a la ciudad de México. Esta información es importante porque ilustra cómo la capital conformó sus estilos de vida y preferencias, más

13 En esta lista se incluye el nombre de Abraham Zabludovsky porque, aun cuando nació en Bialostok, Polonia, sus primeros años, formación y desarrollo, ocurrieron en la ciudad de México. 
acordes con las preferencias de las elites europeas y norteamericanas que con las de sus compatriotas del campo. Salvo, tal vez, las excepciones de Yáñez y Pérez Rayón; el primero por sus evidentes inclinaciones socializantes y nacionalistas y el segundo por haber vivido varios años en Veracruz.

Los arquitectos se enfrentaron entonces al dilema de optar por lo internacional, sinónimo de moderno, o por lo nacional, sinónimo de atraso y arqueología. Cómo renunciar a probar la "modernidad" en una ciudad que se veía provinciana y chaparra. Baste escuchar los comentarios de De la Colina, Mestre, Pani y Yáñez, todos de la primera generación, o de Hernández, González de León y Ortiz Macedo de la segunda, para ver cómo estos arquitectos veían y vivían la ciudad en relación con las europeas y norteamericanas.

Los domicilios familiares de la primera generación de entrevistados se distribuían en la ciudad de México de la siguiente manera: familia Á lvarez en la colonia San Rafael; De la Colina en la Álamos; Gómez Gallardo en las colonias Santa María y San Rafael; Mestre en la Cuauhtémoc; Pani en Santa María la Ribera; De Robina en la de los Doctores y posteriormente en la Juárez; Pérez Rayón y Yáñez en el Centro. Es importante señalar que los arquitectos Álvarez, De la Colina, Pani y De Robina vivieron una larga e importante temporada de sus vidas fuera del país.

Las casas familiares de la segunda generación se localizaban en las siguientes colonias de la ciudad de México: familia González de León en la zona de Cuauhtémoc, San Ángel y finalmente la colonia Hipódromo Condesa; Her- nández en la Condesa; Ortiz Macedo en la Roma y posteriormente Tlalpan; Zabludovsky en La Merced y, tiempo después, en la Hipódromo Condesa. Se debe advertir que las familias de la segunda generación tienen una mayor movilidad espacial dentro de la ciudad; hecho comprensible si se toma en cuenta que la capital aumentó su ritmo de crecimiento a partir de los años veinte.

En cuanto a la definición de la clase a la que pertenecen los informantes, resulta dificil de precisar si se considera que la revolución afectó, en una u otra medida, a todas las familias. De cualquier manera es cierto que la ma. yoría disfrutó de privilegios en una sociedad que ofrecía pocos, aunque unos recibieron muchos más que otros. Resulta dificil comparar los estándares de las familias de Pani, Mestre, Hernández y Ortiz Macedo con los menos acomodados de Yáñez, Pérez Rayón o Zabludovsky. Véanse las reflexiones de Abraham Zabludovsky cuando compara su punto de partida con el de Mario Pani.

Claro, estudiar arquitectura en lugar de ingeniería indicaba, de entrada y en esa época, la pertenencia a una elite. Conviene aclarar que en San Carlos se inscribían, según Yáñez, los señoritos y los nobles; en cambio a la Escuela Superior de Ingeniería y Arquitectura (ESIA) del Politécnico, fundada en los treinta, asistían los jóvenes de las clases media y media baja, como lo aclaró Pérez Rayón.

Existen, sin embargo, situaciones más difíciles de evaluar, como el caso de Abraham Zabludovsky, hijo de intelectuales, maestros, inmigrantes ju- 
díos de Polonia, residentes en La Merced y al parecer desprovistos de muchos recursos al momento de su llegada a México.

Enrique Yáñez y Reinaldo Pérez Rayón se autopresentaron como miembros de familias de clase media pero sin problemas apremiantes. Reconocieron que vivian bien pero no disponían de lujos.

Sólo algunos de los entrevistados comentaron la vinculación de sus familias con las elites sociales, intelectuales, políticas, profesionales y militares de la historia mexicana. Véanse los antecedentes de Mario Pani, Héctor Mestre, Augusto H. Álvarez, Ernesto Gómez Gallardo, Teodoro González de León, Agustín Hernández y Luis Ortiz Macedo: algunos de ellos hijos de políticos, militares, profesionales exitosos, hacendados o comerciantes.

De los doce entrevistados, todos contaron con carrera profesional y título universitario, algunos hasta con distinción académica. Manuel de la Colina y Mario Pani, de la primera generación, cursaron parcial o totalmente la carrera en Estados Unidos y Francia respectivamente. Teodoro González de León y Luis Ortiz Macedo, de la segunda generación, realizaron sus estudios de posgrado y preparación superior en arquitec. tura principalmente en Francia y algunos otros lugares de Europa. Conviene mencionar que los arquitectos mexicanos no acostumbraban solicitar becas para formarse en el extranjero. Incluso González de León es el único mexicano de su generación que trabajó con un arquitecto extranjero: Le Corbusier.

La educación de la mayoría se acer- ó al modelo europeo, de preferencia al francés, y al norteamericano, para el caso de los alumnos de San Carlos. En cambio, maestros y alumnos de la ESIA se identificaron con los estudios avanza. dos de la Bauhaus. Véanse los casos de Yáñez y Pérez Rayón respectivamente.

Todos los arquitectos entrevistados cuentan con reconocimientos, premios, o forman parte de importantes sociedades internacionales de arquitectos. Las obras de los entrevistados se publicaron, muchas de ellas, en las más prestigiadas revistas extranjeras de arquitectura. La búsqueda del reconocimiento internacional probaba el carácter del grupo como elite intelectual.

Los informantes pertenecientes a familias con perfiles excepcionales, como Mario Pani y Manuel de la Colina -cuyos padre y hermano fueron diplo. máticos en Francia y Estados Unidos respectivamente- aprendieron los idiomas, francés e inglés, desde su infancia. Héctor Mestre adquirió su conocimiento del inglés por su educación en un colegio inglés en México y a través de numerosos viajes a Estados Unidos. Ricardo Robina conoció los idiomas desde su educación en España. Augusto H. Álvarez aprendió el francés en el colegio Francés Morelos. Enrique Yáñez recibió lecciones de francés, por una corta temporada, en el Colegio Francés, aunque probable. mente haya aprendido los idiomas en las revistas y libros de arquitectura y, claro, a través de sus propias experiencias profesionales. Ernesto Gómez Gallardo estudió las lenguas extranjeras en el Instituto Franco Inglés, educación que, dijo, agradece mucho a su padre. 
En el caso de la segunda generación, Teodoro Gonzālez de León absorbió las primeras nociones del francés a través de su madre, del Colegio Francés y, por supuesto, de su estancia en París como dibujante en el despacho de Le Corbusier. Luis Ortiz Mace. do probablemente estudió los idiomas con los lasallistas y posteriormente en Europa. Tal vez Abraham Zabludovsky y Reinaldo Pérez Rayón, formados en escuelas oficiales, complementaron su conocimiento de los idiomas me diante esfuerzos personales y a lo largo de su propia carrera. Agustín Hernán dez parece haber asimilado los idiomas en forma independiente.

En cuanto al manejo de lenguas extranjeras se puede decir que los arquitectos no representan un conjunto excepcional, ya que esta herramienta les resultaba indispensable para viajar y enterarse, en las revistas, de los avances de la arquitectura moderna en Europa y Estados Unidos.

Como fuente de inspiración los arquitectos abandonaron las lecciones de la Escuela de Bellas Artes de París para sincronizar sus pensamientos, ya fuera con las enseñanzas apuntadas por el propio Le Corbusier en sus libros -más que teorías, verdaderas doctrinas o llamados de conciencia-, o con las demostraciones y teorías sistematizadas en la Bauhaus.

A mbas generaciones recibieron una buena dosis de información de los profesionales europeos que emigraron a Estados Unidos y a México. Recuérdense los nombres de Félix Candela, Hannes Meyer, Vladimir Kaspé y Max Cetto, por decir sólo algunos.

Las dos generaciones, vieja y joven, están interconectadas, académica e ideológicamente, por un nexo común: la modernidad, asociada al "progreso". Curiosamente ésta es la palabra clave para entender buena parte del pensamiento latinoamericano de aquella época.

\section{Los estilos de vida}

Lagran mayoría de los arquitectos entrevistados trabajaron o se asociaron, en una etapa de su desarrollo profesional, con alguno de los grandes maestros de la arquitectura. Esto les permitió establecer la relación maestro-aprendiz que les garantizó el aprendizaje del oficio. Lamentablemente, ahora, por la complejidad urbana, esta liga ha desaparecido. Los arquitectos atribuyen a este cambio buena parte de la falta de calidad de la arquitectura contemporánea mexicana, ya que en la actualidad los alumnos asimilan los conocimientos de maestros malos que no tienen trabajo ni práctica. Para mí, este rompimiento tiene adenás otra consecuencia importante: la descomposición de la propia elite.

En una segunda etapa de su carrera profesional, los arquitectos que disponúan de relaciones sociales, dinero y contactos políticos instalaron su propio despacho. Los que carecían de estos elementos se incorporaron al Estado o ejercieron actividades afines a la arquitectura, como la construcción, la venta de materiales o de bienes raíces. En este renglón debe recordarse, primero, que la industria de la construcción mexicana, por demanda de obras y oferta de recursos financieros, nació ligada al Estado mexicano, y segundo, 
que las edificaciones más importantes, en volumen y alcances sociales, las hizo el gobierno. ${ }^{14}$ Esto unió los recursos de la elite profesional de arquitectos con el poder del Estado. De ahí que sea correcta la definición del grupo de los arquitectos -de las generaciones estudiadas- como una elite y, como tal, uno de los puntos de partida para la formación de la elite gobernante.

Esto explica por qué en una tercera etapa de su desarrollo los arquitectos se dividieron en tres tipos, que perduran hasta la fecha, pero que tendrán que cambiar en el futuro: 1) los que se dedicaron a trabajar para el sector privado como Mestre, De la Colina y Álvarez; 2) los que realizaron principalmente obra oficial como Yáñez y Pérez Rayón, y 3) los que desarrollaron una actividad de tipo mixto, es decir, entre el sector privado y el oficial, como serían Mario Pani, Ricardo de Robina, Ernesto Gómez Gallardo, Teodoro González de León, Abraham Zabludovsky, Agustín Hernández y Luis Ortiz Macedo. La división es arbitraria, pues a veces se entremezclan las categorías.

Para acceder al mercado de trabajo existían dos alternativas: 1) lograr encargos privados mediante contactos sociales, y 2) participar con buenos proyectos en los concursos que entonces se acostumbraba abrir y ganar con honestidad. En realidad sólo participaban unos cuantos arquitectos, pues la plantilla de profesionales capacitados era limitada. Generalmente competían entre diez y doce arquitectos. Sin embargo parece que los concursos

${ }^{14}$ Ball y Collony, "Capital", 1987, p. 156. ayudaron a todos, fundamentalmente cuando a unos se les acabaron los contactos sociales de sus familias, $y$ a otros la oferta de trabajo les parecía un sueño. Los concursos reciclaban y recirculaban a la elite cerrada de arquitectos, que al abrirse se revitalizaba y ofrecía oportunidades a nuevos talentos.

\section{De ideas y obras}

La elite arquitectónica, al vincularse a la elite gubernamental identificada con las ideas de modernidad y progreso vigentes en las ciudades europeas y norteamericanas, se enfrentó a la dificil tarea de elegir entre tres principales tendencias arquitectónicas: la internacional, representada por la Bauhaus, Le Corbusier y, posteriormente, Ludwig Mies van der Rohe; el realismo socialista de la Unión Soviética, respaldado por los grupos de izquierda a pesar de su pésima calidad y falta de estética, y la tendencia nacionalista que impulsaba la imitación de los estilos prehispánicos y coloniales. La arquitectura que predominó fue la internacional, porque ésta coincidía plenamente con los deseos de industrialización, progreso y modernidad que añoraban las elites gobernantes en los años cincuenta, e incluso hasta la actualidad.

La arquitectura vernácula no reflejaba el modernismo de la época ni se adaptaba a las ideas de prefabricación que los arquitectos supusieron resolverían las demandas de habitación, escuelas, vivienda y espacios de trabajo para una población en crecimiento. La elite gobernante y la arquitectura adop- 
taron el modelo de la modernidad, que alguna vez tuvo su legitimidad, para dibujar el perfil de la ciudad de México del siglo Xx. Véanse las dificultades de Ricardo de Robina y Luis Ortiz Macedo para involucrar a sus respectivas generaciones en el urgente compromiso de salvar el patrimonio arquitectónico nacional.

Sin embargo, ¿cómo explicar los grandes momentos de esta elite que se registran al realizarse el Plan Nacional de Construcción de Hospitales; la planificación y construcción de escuelas con el CAPFCE; la edificación de multifamiliares; el desarrollo del proyecto de Ciudad Universitaria; la realización de la Unidad Zacatenco del Instituto Politécnico, el Colegio Militar, el Colegio de México o el conjunto habitacional Mixcoac Lomas de Plateros?

Ciertamente los arquitectos adopta. ron formas o modelos extranjeros para expresarse, pero las demandas sociales y los recursos técnicos, materiales y financieros del país obligaron a proyectistas, constructores y políticos a buscar una sintesis que llevara a una arquitectura nacional.

Otra explicación importante para interpretar esta síntesis nacional, creo que se debe atribuir a la amplia participación en estos proyectos, principalmente en el de la Ciudad Universitaria, de un grupo de arquitectos de todas las tendencias formales e ideológicas. La democratización de la elite permitió su enriquecimiento intelectual y artísticoy finalmente la tan anhelada sintesis.

En cuanto a la arquitectura privada, dedicada a los espacios administrativos y financieros, las preocupaciones nacionalistas quedaron marginadas.
Simplemente, como explicó Héctor Mestre, había que proyectar espacios acordes con "la manera moderna de trabajar" que lógicamente México debía aprender de Estados Unidos, concretamente de Nueva York, el centro mundial de los negocios.

¿Cuáles serían entonces las aportaciones de Álvarez, De la Colina, Mestre y Gómez Gallardo a la arquitectura mexicana contemporánea? Por una parte, su reinterpretación de las formas internacionales y, principalmente, el haber logrado convencer a los dueños de bancos, aseguradoras, firmas comerciales, industrias y fábricas, de que los espacios de trabajo deben ser amables, y que los empleados que los ocupan son algo más que máquinas: seres humanos con derecho a disfrutar de la belleza.

La apertura vivida en esos años de creatividad ofreció una experiencia espléndida, aunque algunos quedaron fuera por sus diferencias profesionales con las cabezas. Véase el distanciamiento de González de León del maestro Pani. El elitismo estrecho del grupo actual y su concentración del poder explica en gran parte el estancamiento de la arquitectura mexicana y la crisis de su gremio como un conjunto de profesionales separado de los que deciden los rumbos de la construcción de la ciudad.

\section{CONCLUSIONES}

El tipo de investigación y las características de los datos registrados (estadísticamente no representativos y numéricamente muy escuetos) impide 
hacer afirmaciones en cuanto al alcance y generalidad de los patrones identificados. Sin embargo, la particularidad de los fenómenos que se observaron en forma individual sugieren su importancia y la necesidad de estudiarlos.

No obstante, al investigar estas dos generaciones de arquitectos me parece que las ideas de modernización e internacionalización marcaron sus pensamientos y estilos de vida. Lo nacional se restringió a la arqueología y a la nostalgia que ahora buscan recobrar. Paradójicamente, ahora lo vernáculo y la hightech contemporánea se disputan la vanguardia.

El predominio de las ideas progresistas e internacionales que definieron a esa elite de arquitectos comprueba la habilidad y talento del grupo para subsistir como elite, prolongarse en las generaciones siguientes y confundirse con las elites gobernantes para mantener viva su presencia en la arquitectura de fines del siglo $x x$.

Esa generación de arquitectos, aunque elitista por su composición y enfoques, pasó de las expresiones constructivas de un grupo a una arquitectura nacional al establecer los concursos y la competencia como instrumentos necesarios para regular su poder y calidad. Desaparecidos estos mecanismos, la elite se encerró en sí misma y perdió la posibilidad de renovarse que le ofrecía el conocimiento del "otro" dentro y fuera de sí. La recirculación de la elite cesó y, con ella, la existencia de la propia elite. La elite de arquitectos muere, y lo más grave es que lo hace sin dejar descendientes que devuelvan la coherencia y belleza a esta que alguna vez alguien llamó "la ciudad de los palacios".

\section{BibLIOGR AFÍA}

-Ball, Michael y Prisilla Connolly, "Capital accumulation in the mexican construction industry, 1930-1982", International Jour. nal of Urban and Regional Research, vol. 11 , núm. 2, junio 1987.

-Bottomore, T. B., Elites and society, Penguin Books, Gran Bretaña, 1964-1973.

-Boudon y Bourricaud, "Elites", $A$ critical dictionary of sociology, selección y tra. ducción de Peter Hamilton, The University of Chicago Press, Chicago, 1980.

-Burns, Bradford E., "Ideology in nineteenth-century latin american historiography", The Hispanic American Historcal Review, vol. 58, núm. 3, agosto 1978, pp. 409-431.

-Carr, Edward Harlet, What is history?, 2a. ed., editada por R. W. Davies, The Macmillan Press Ltd., Hong Kong, 1986.

-Peattie, Lisa R., "Planning and the image of the city", Places, vol. 7, núm. 2, invierno 1991, pp. 35-39.

-Polledri, Paolo, "Dreamscape, reality and afterthoughts", Places, vol. 7, núm. 2, invierno 1991, pp. 8-20.

-Saraceno, Chiara, "La estructura tem. poral de las biografias", Historia y fuente oral, núm. 2, 1989, pp. 41-49.

-Tarkowska, Ezbieta, "Diferenciación de estilos de vida en Polonia: generación y sexo", Historia y fuente oral, núm. 5 , 1991, pp. 47-70. 